\title{
LETTER
}

\section{Benefits of high dose clofazimine}

\author{
C. Ruth Butlin ${ }^{\mathrm{a}, \mathrm{b}}$ \& Armi Maghanoy ${ }^{\mathrm{c}}$ \\ ${ }^{a}$ The Leprosy Mission England \& Wales, Goldhay Way, Orton Goldhay, \\ Peterborough, UK \\ ORCID: https://orcid.org/0000-0001-7008-5263 \\ ${ }^{\mathrm{b}}$ The Leprosy Mission International Bangladesh, DBLM Hospital and Rural \\ Health Programmes, Mohakhali New DOHS, Dhaka, Bangladesh \\ ${ }^{\mathrm{c}}$ Leonard Wood Memorial Center for Leprosy Research Cebu, Philippines
}

Submitted 11 October 2021; Accepted 3 November 2021

\begin{abstract}
Summary Besides its role in multidrug therapy, clofazimine at higher doses is widely used for relief of Type 2 (ENL) reaction in leprosy. There is a lack of evidence from clinical trials regarding indications, optimum regimen and risk/benefit ratio to support published guidelines on its use as an anti-reaction drug. Clinical experience suggests that in adults it is safe at high doses (up to $300 \mathrm{mg} /$ day) for limited periods of time but caution is needed with patients of low body weight and in those taking other drugs which may interact.
\end{abstract}

Keywords: Clofazimine, ENL, type 2 reaction, adverse effects, steroid-sparing, guidelines

Dear Editor,

\section{Benefits of high dose clofazimine}

Clofazimine has been used in treatment of leprosy for over 50 years. It has mild bactericidal action against $M$. leprae as well as having suppressive effect on erythema nodosum leprosum (ENL). ${ }^{1-8}$ When the reduction in length of treatment with MDT from 24 months to 12 months for multibacillary cases, as advised by the World Health Organization (WHO), was implemented, it was noted that ENL appeared to be more of a problem. ${ }^{6,9}$ This was thought to be a result of patients receiving less clofazimine.

Clofazimine may indirectly interfere with the proliferation of T lymphocytes by promoting the release of E-series prostaglandins (PGs), especially PGE2 from neutrophils and monocytes which may have a significant role in controlling Type 2 reactions. However, its effect is only apparent when a certain critical level is reached. Sustained tissue levels of clofazimine may be more important than peak blood levels for its therapeutic effect. ${ }^{7,10,11}$ 
Many practising clinicians believe it is useful as an adjunct to steroids for managing ENL reactions, yet there is a dearth of published evidence from trials to show whether it is effective at high doses, either to prevent first episodes or to reduce recurrence of ENL, or for its steroidsparing effect in chronic ENL, and very little evidence to determine the best regimen for ENL management. Different doses and durations may be found to be appropriate for each scenario.

In a double-blind controlled trial by Karat et al. ${ }^{12}$ There were 24 lepromatous leprosy patients in reaction who were randomly allocated to receive either clofazimine or prednisolone for 12 weeks and were followed-up for more than 4 months. It showed that clofazimine controlled symptoms of ENL reaction better than prednisolone. It also appeared to be significantly superior in preventing recurrence once the reaction had been controlled. There was no difference in terms of neurological status, bacterial index, morphological index, and renal function among inpatients on clofazimine, as compared with patients on prednisolone; the observed statistically significant rise in serum albumin may not be clinically important. Red/black hyperpigmentation was seen among practically all patients on clofazimine. No other side-effects or deleterious systemic effects were observed.

Recent studies with MDT-treated patients include a retrospective study done by Balagon et $a l .{ }^{6}$ comparing two cohorts, involving 589 patients who were receiving either 12 or 24 months MBMDT and followed for at least 4 years. This study showed that ENL was not significantly more common, but it was longer-lasting and more severe in patients receiving only 12 months of MDT, as compared with those receiving 24 months treatment.

This was followed by a double-blind study, comparing 100 patients randomly allocated to either $100 \mathrm{mg}$ daily clofazimine or placebo for 12 months after completion of 12 months MBMDT. The outcome measures used were a newly developed ENL severity scoring system, total steroid intake, incidence of new ENL episodes and duration of episodes. On some measures, including deaths likely to be related to steroid intake, the placebo group appeared to have more severe ENL, but none of the differences were statistically significant. ${ }^{13}$

The guidelines suggested by WHO for managing severe, chronic ENL with clofazimine ( $300 \mathrm{mg}$ /day for 12 weeks, taper to $200 \mathrm{mg} /$ day for 12 weeks then $100 \mathrm{mg} /$ day for $12-24$ weeks), ${ }^{6}$ are widely used and seem beneficial. A gradual improvement of ENL symptoms, steroid-sparing effect and preventing episodes of recurrence are observed among patients. However, none of the various guidelines or recommendations available (see Table $1^{10,14-21}$ ) are based on results of good quality clinical trials supported by objective criteria and many clinicians use different regimens; consensus on best practice is still lacking. The precise indications for appropriate use of high dose clofazimine (both for ENL patients on MDT and for those who suffer ENL after release from treatment) need to be clarified.

Reversible dose-related skin discoloration, is the most common side effect of clofazimine. Whilst aesthetically undesirable it is not physically harmful and in many people with naturally darker skin tones this is tolerable. The associated xeroderma or ichthyosis, especially on exposed areas, is more problematic. Most studies of adverse effects of clofazimine in leprosy do not enumerate these "expected effects". ${ }^{22-25}$ Dermatological effects rarely lead to discontinuation of the drug in TB cases. ${ }^{26}$. Used with other drugs for TB, clofazimine is associated with gastrointestinal side effects in $40-55 \%$ cases. ${ }^{27,28}$ At present, there is still no accurate assessment as to the frequency, nature and incidence of the gastro-intestinal side effects occurring with high dose clofazimine when used for leprosy. Nausea, and diarrhoea have been reported as commonly mild; weight loss has been observed occasionally, while severe abdominal pain is rare. ${ }^{29}$ However, a retrospective study of the use of clofazimine in TB showed a clear association between skin or gastrointestinal adverse effects and the 


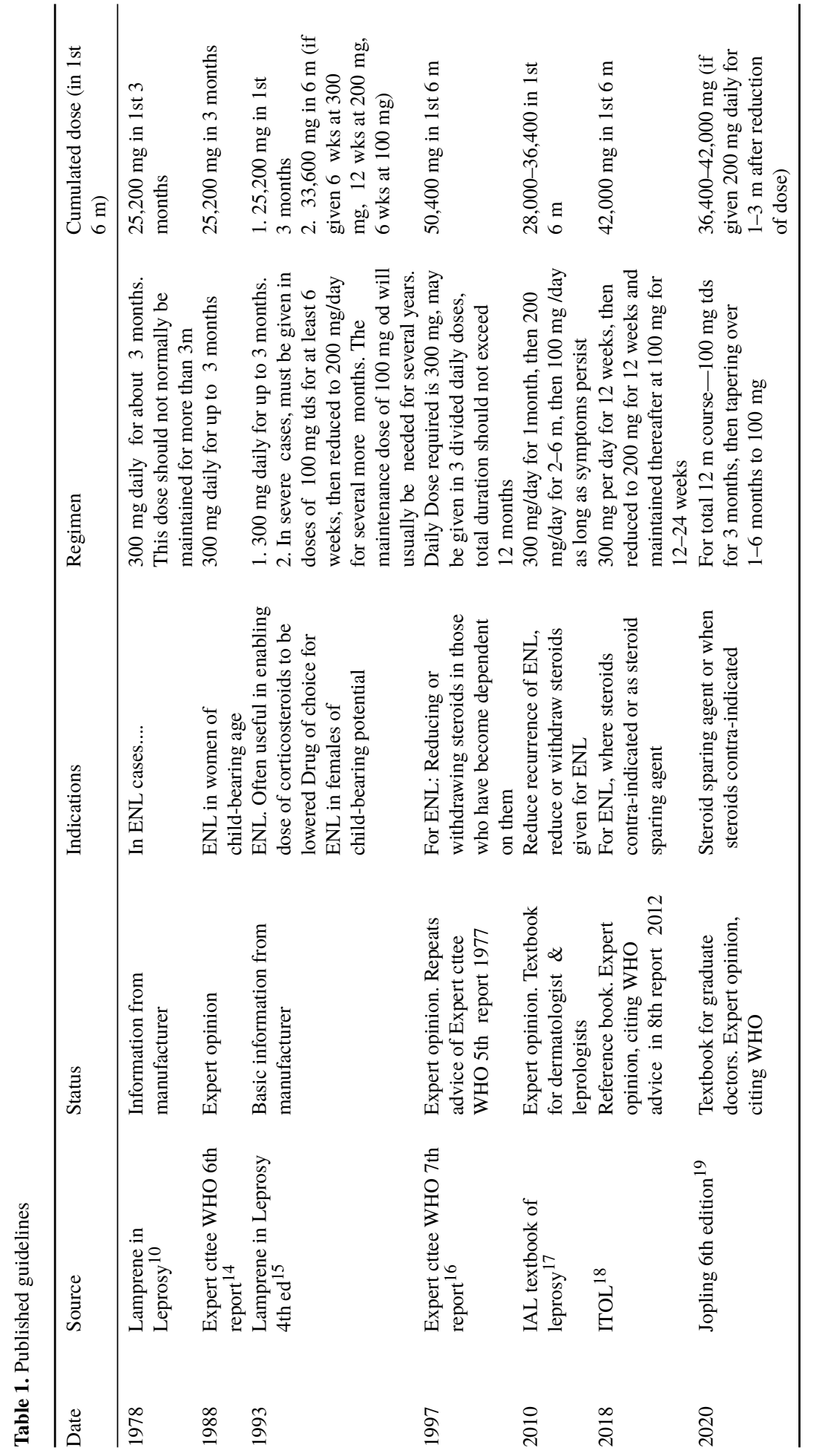




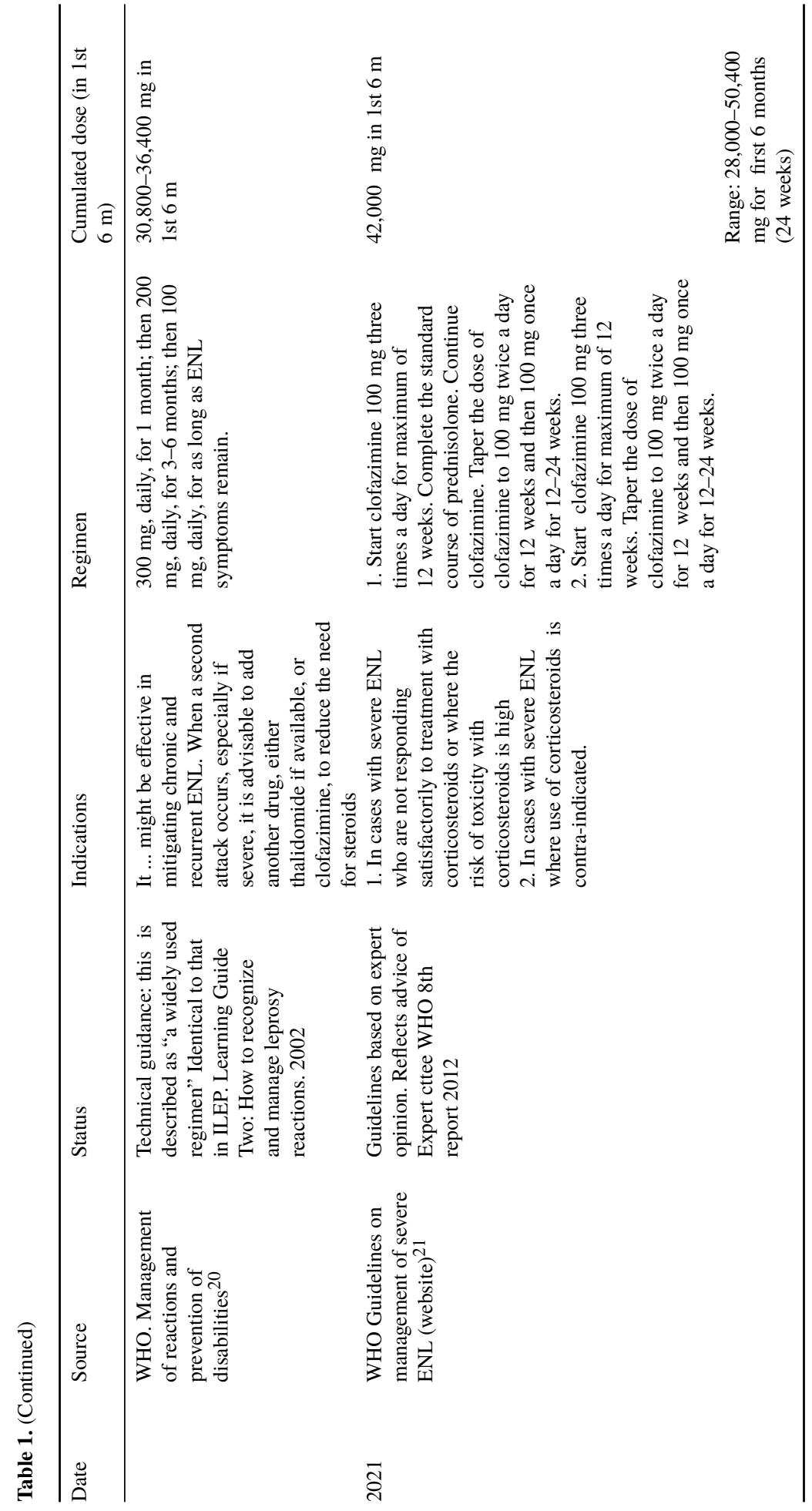


combination of low body weight with higher drug dosage. ${ }^{30}$ Other serious adverse effects, such as pulmonary crystal deposition ${ }^{31,32}$ and cardiac dysrhythmias, ${ }^{33,34}$ are rare and mainly reported in patients receiving other drugs which interact, those with other medical conditions, and people who have received high dose clofazimine for excessively long periods. An early prospective study of people on high dose clofazimine for 2-8 years found no clinically significant effects on renal function, liver function or haematological parameters. ${ }^{35}$

Therefore, clofazimine is a relatively safe and a useful drug due to its anti-bacterial and anti-inflammatory effect. It is suitable for patients with steroid dependency, having recurrent ENL. As to its role in preventing the first occurrence of ENL, it has not yet been proven but this might be possible with high dose clofazimine. Future studies should be considered, preferably good quality randomised clinical trials supported by large sample size, with both specific eligibility criteria and objective criteria used for outcome measures. A study targeting patients who already had at least one episode of ENL, which has already obtained ethical approval and has funding approved by the Leprosy Research Initiative, will be conducted soon to validate the effect of high dose clofazimine in these patients. Whether or not extended coverage with clofazimine should also be given to those lepromatous and borderline lepromatous leprosy patients who are at high risk of developing ENL (but have not yet had a first episode), is still uncertain.

\section{References}

1 Browne SG. "B663”. Possible anti-inflammatory action in lepromatous leprosy. Lepr Rev, 1965; 36(1): 9-11.

2 Browne SG. B663 (Geigy). Further observations on its suspected anti-inflammatory action. Lepr Rev, 1966; 37(3): 141-145.

3 Waters MFR. G30 or B663. A working party held at the Royal Garden Hotel, London, September 1968. Lepr Rev, 1969; 40(1): 21-47.

4 Schultz. Forty-four months experience with clofazimine. Lepr Rev, 1972; 42(3): 178-187.

5 Cellona RV, Fajardo TT Jr, Kim DI, Hah YM, Ramasoota T, Sampattavanich S, Carrillo MP, Abalos RM, dela Cruz EC, Ito T et al. Joint chemotherapy trials in lepromatous leprosy conducted in Thailand, the Philippines, and Korea. Int J Lepr Other Mycobact Dis, 1990; 58(1): 1-11.

6 Balagon M, Saunderson PR, Gelber RH. Does clofazimine prevent erythema nodosum leprosum (ENL) in leprosy? A retrospective study, comparing the experience of multibacillary patients receiving either 12 or 24 months WHO-MDT. Lepr Rev, 2011; 82(3): 213-221.

7 Helmy HS, Pearson JM, Waters MF. Treatment of moderately severe erythema nodosum leprosum with clofazimine-a controlled trial. Lepr Rev, 1971; 42(3): 167-177. doi:10.5935/0305-7518.19710020. PMID: 4339652.

8 Karat AB, Jeevaratnam A, Karat S, Rao PS. Efficacy of clofazimine in the prophylaxis and suppression of reactive phases of lepromatous leprosy. Int J Lepr Other Mycobacterial Dis: Official Organ of the Int Lepr Assoc, 1971; 39(4): 838-841. PMID: 5170472.

9 Walker SL, Balagon M, Darlong J, Doni SN, Hagge DA, Halwai V, John A, Lambert SM, Maghanoy A, Nery JA, Neupane KD, Nicholls PG, Pai VV, Parajuli P, Sales AM, Sarno E, Shah M, Tsegaye D, Lockwood DN. Erythema nodosum leprosum international study group. ENLIST 1: An international multi-centre cross-sectional study of the clinical features of erythema nodosum leprosum. PLoS Negl Trop Dis, 2015; 9(9): e0004065. doi:10.1371/j ournal.pntd.0004065. PMID: 26351858; PMCID: PMC4564249.

10 Yawalkar SJ, Vischer W. Lamprene (clofazimine) in leprosy. Basic information. Lepr Rev, 1979; 50(2): $135-144$. doi:10.5935/0305-7518.19790020. PMID: 396428.

11 Berghem L, Lahnborg G, Schildt B. Does clofazimine (LamprenR) affect the macro- and microphage function in man? J Reticuloendothel Soc, 1977; 21(3): 171-173. PMID: 886539.

12 Karat AB, Jeevaratnam A, Karat S, Rao PS. Double-blind controlled clinical trial of clofazimine in reactive phases of lepromatous leprosy. Br Med J, 1970; 1(5690): 198-200. doi:10.1136/bmj.1.5690.198. PMID: 4904 935; PMCID: PMC1699291.

13 Maghanoy A, Balagon M, Saunderson P, Scheelbeek P. A prospective randomised, double-blind, placebo controlled trial on the effect of extended clofazimine on erythema nodosum leprosum (ENL) in multibacillary (MB) leprosy. Lepr Rev, 2017; 88: 208-216. doi:10.47276/1r.88.2.208. 
14 WHO expert committee on leprosy. 6th Report. Technical Report Series 768, WHO, Geneva, 1988.

15 Yawalker SJ. Lamprene (Clofazimine) in Leprosy, Basic Information. 4th edn, Switzerland: CIBA-GEIGY Ltd, 1993.

16 WHO Expert Committee on Leprosy. 7th Report, 1997. Technical Report Series 874, WHO, Geneva, 1998.

17 Hemanta KK, Bhushan K (eds) IAL Textbook of Leprosy. New Delhi: Jaypee Brothers, 2010.

18 Walker S. Chapter 2.2 reactions. ITOL. 2018. available online www.internationaltextbookofleprosy.org.

19 Sardana K, Khurana A (eds) Jopling. 6th edn, New Delhi: CBS Publishers \& Distributors, 2020.

20 WHO. 2020. Management of reactions and prevention of disabilities. Technical Guidance. New Delhi: World Health Organization, Regional Office for South-East Asia; 2017. Published WHO 2020.

21 WHO. Guidelines for the management of severe erythema nodosum leprosum (ENL) reactions. Downloaded 16.3.21 from www.WHO.int. https://www.who.int/lep/research/WHOenlguide.pdf. https://www.who.int/lep/m $\mathrm{dt} /$ clofazimine/en.

22 Deps Patricia D, Nasser S, Guerra P, Simon M, De Ca' Ssia Birshner R, Rodrigues LC. Adverse effects from multi-drug therapy in leprosy: a Brazilian study. Lepr Rev, 2007; 78: 216-222.

23 Tortelly VD, Daxbacher EL, Brotas AM, Sueli. Adverse effects of polychemotherapy for leprosy in 13 years of follow-up at a university hospital. An Bras Dermatol, 2021; 96: 224-227.

24 Singh H, Nel B, Dey V, Tiwari P, Dulhani N. Adverse effects of MDT in leprosy a two year experience (20062008) in tertiary health centre in the tribal region of Chhattisgarh state (Bastar, Jagdalpur). Lepr Rev, 2011; 82(1): 17-24.

25 Moore VJ. Review of side effects experienced by patients taking clofazimine. Lepr Rev, 1983; 54: 327-335.

26 Hwang TJ, Dotsenko S, Jafarov A et al. Safety and availability of clofazimine in the treatment of multidrug and extensively drug-resistant tuberculosis: analysis of published guidance and meta-analysis of cohort studies. BMJ Open, 2014; 4: e004143. doi:10.1136/bmjopen-2013-004143.

27 Dalcolmo M, Gayoso R, Sotgiu G et al. Effectiveness and safety of clofazimine in multidrug-resistant tuberculosis: a nationwide report from Brazil. Eur Respir J, 2017; 49: 1602445. https://erj.ersjournals.com/content/49 /3/1602445.long.

28 Martiniano SL, Wagner BD, Levin A, Nick JA, Sagel SD, Daley CL. Safety and effectiveness of clofazimine for primary and refractory nontuberculous mycobacterial infection. Chest, 2017; 152(4): 800-809.

29 Bryceson A. Unnecessary laparotomy for abdominal pain and fever due to clofazimine. Lepr Rev, 1979; 50(3): 258-259.

30 Misra N, Padayatchi N, Naidoo P. Dose-related adverse events in South African patients prescribed clofazimine for drug-resistant tuberculosis. South African Med J, 2020; 110(1): 32-37. doi:10.7196/SAMJ.2019.v110i1.13 954.

31 Wu Q, Ganzert C, Lücke E, Bittmann I, Schreiber J. Fatal course of clofazimine-induced pulmonary crystal deposition in a patient with Melkersson-Rosenthal syndrome. Int J Clin Pharmacol Therapeut, 2020; 58(9): $518-522$.

32 Alfandari S. Pulmonary clofazimine crystals in two patients with the acquired immunodeficiency syndrome. Int J Tuberculosis Lung Dis, 1997; 1: 88-89.

33 Choudhri Shurjeel H, Louise H, Butany JW, Keystone Jay S. Clofazimine induced cardiotoxicity—a case report. Lepr Rev, 1995; 66: 63-68.

34 Zweijpfenning S, van Groningen $\mathrm{H}$ et al. Clozafimine does not lead to significant QT interval prolongation: a multicentre study. Eur Respir J, 2018; 52: 1801386. https://erj.ersjournals.com/content/52/5/1801386.long.

35 Hastings RC, Jacobson RR, Trautman JR. Long-term clinical toxicity studies with clofazimine in leprosy. Int $J$ Lepr, 1976; 44: 293. 